\title{
Aberrant Function of the Ras-Related Protein TC21/R-Ras2 Triggers Malignant Transformation
}

\author{
SUZANNE M. GRAHAM, ${ }^{1}$ ADRIENNE D. COX, ${ }^{2}$ GEORGE DRIVAS, ${ }^{3}$ MARK G. RUSH, ${ }^{4}$ \\ PETER D'EUSTACHIO, ${ }^{4}$ AND CHANNING J. DER ${ }^{1,2 *}$ \\ Curriculum in Genetics and Molecular Biology ${ }^{1}$ and Department of Pharmacology, School of Medicine and Lineberger \\ Comprehensive Cancer Center, ${ }^{2}$ University of North Carolina at Chapel Hill, Chapel Hill, North Carolina 27599; \\ Brookdale Center for Molecular Biology, Mount Sinai School of Medicine, New York, New York 100293; and \\ Department of Biochemistry, NYU Medical Center, Kaplan Cancer Center, New York, New York $10016^{4}$
}

Received 13 January 1994/Returned for modification 25 February 1994/Accepted 10 March 1994

\begin{abstract}
Although the human Ras proteins are members of a large superfamily of Ras-related proteins, to date, only the proteins encoded by the three mammalian ras genes have been found to possess oncogenic potential. Among the known Ras-related proteins, TC21/R-Ras2 exhibits the most significant amino acid identity (55\%) to Ras proteins. We have generated mutant forms of TC21 that possess amino acid substitutions analogous to those that activate Ras oncogenic potential [designated TC21(22V) and TC21(71L)] and compared the biological properties of TC21 with those of Ras proteins in NIH 3T3 and Rat-1 transformation assays. Whereas wild-type TC21 did not show any transforming potential in vitro, both TC21(22V) and TC21(71L) displayed surprisingly potent transforming activities that were comparable to the strong transforming activity of oncogenic Ras proteins. Like Ras-transformed cells, NIH 3T3 cells expressing mutant TC21 proteins formed foci of morphologically transformed cells in monolayer cultures, proliferated in low serum, formed colonies in soft agar, and developed progressive tumors in nude mice. Thus, TC21 is the first Ras-related protein to exhibit potent transforming activity equivalent to that of Ras. Furthermore, mutant TC21 proteins also stimulated constitutive activation of mitogen-activated protein kinases as well as transcriptional activation from Ras-responsive promoter elements (Ets/AP-1 and NF-KB). We conclude that aberrant TC21 function may trigger cellular transformation via a signal transduction pathway similar to that of oncogenic Ras and suggest that deregulated TC21 activity may contribute significantly to human oncogenesis.
\end{abstract}

The three human ras genes encode four closely related $(\mathrm{H}-$-, $\mathrm{N}-$, K4A-, and K4B-Ras) proteins that have been a major focus of interest because of the high incidence of mutated forms in human tumors $(2,8,13)$. Normal Ras proteins function as molecular switches that are controlled by a regulated GDP/ GTP cycle (9). Guanine nucleotide exchange factors (GEFs; e.g., SOS and mCDC25/GRF) promote formation of the active, GTP-bound Ras $(20,35)$, whereas GTPase-activating proteins (GAPs; p120 and NF1 GAP) promote formation of the inactive, GDP-bound Ras (7). Each oncogenic Ras protein possesses a single amino acid substitution at residue 12,13 , or 61 , which renders it insensitive to the negative regulatory functions of GAPs. Consequently, these proteins are defective in cycling and persist in a chronically active, GTP-bound state (9).

Ras proteins are members of a large superfamily (>50 mammalian members) of GTP-binding proteins. Ras-related proteins share significant size $(20$ to $25 \mathrm{kDa})$ and sequence identity $(30$ to $55 \%$ ) with Ras proteins $(6,49)$. Like Ras, the other members of this family are also believed to function as regulated molecular switches that control a spectrum of diverse cellular processes $(6,9,49)$. While recent studies have established the role of Ras proteins in signal transduction pathways that control cell growth and differentiation $(6,27)$, Rab proteins have been shown to be important regulatory components of intracellular transport (39), and Rho proteins function as regulators of the actin cytoskeletal organization $(46,47)$.

* Corresponding author. Mailing address: University of North Carolina at Chapel Hill, CB 7365, FLOB, Chapel Hill, NC 27599. Phone: (919) 966-5634. Fax: (919) 966-5640. Electronic mail address: cjder@ med.unc.edu.
$\mathrm{Ran} / \mathrm{TC} 4(19,43)$ is a regulator of both cell cycle progression and the nuclear-cytosolic trafficking of RNA and protein $(4,34$, 37). Finally, although Krev-1/Rap1a shows strong (50\%) amino acid identity with Ras proteins, this Ras-related protein has been found to be an antagonist of Ras transforming activity $(15,30)$.

Despite the strong structural and biochemical similarities between Ras and Ras-related proteins, to date, only Ras proteins have been shown to possess oncogenic properties. The general approach in these studies has been to introduce amino acid substitutions into Ras-related proteins that are analogous to those that render Ras proteins constitutively GTP bound and cause activation of Ras transforming potential. For example, the introduction of such mutations into Krev-1 potentiated its Ras-suppressing activity rather than converting Krev-1 into a transforming protein (29). Neither the wild-type protein nor a Gly-12 $\rightarrow$ Val $(12 \mathrm{~V})$ version of R-Ras, which shares strong $(55 \%)$ identity to Ras proteins, showed any transforming activity in Rat-1 cell transformation assays (32). Conflicting results have been reported for Rho proteins. Whereas it was first observed that overexpression of wild-type, but not mutant, RhoA protein caused weak cellular transformation of NIH 3T3 cells (1), a recent study described the reverse situation, in which a mutant form of Aplysia Rho (12V equivalent) showed weak transforming activity in NIH 3T3 transformation assays (40). Finally, a third study showed that mutant human RhoA induced weak focus-forming activity but did not significantly alter the growth properties of cells expressing this mutant RhoA protein (48). Nonetheless, despite the different observations from these studies, there is agreement that Rho proteins do not exhibit the potent transforming capabilities of oncogenic Ras proteins. 
TC21 is a member of the Ras superfamily and shares $55 \%$ amino acid identity with Ras proteins (19). Since TC21 shares strongest identity $(\sim 70 \%)$ with another Ras-related protein, designated R-Ras (32), we suggest that TC21 be referred to as R-Ras2 (the Ras-related Rap1 and Rap2 proteins share $\sim 70 \%$ identity). Little is known about TC21/R-Ras 2 regulation or function. However, since TC21 shares complete identity with Ras residues important for regulation by Ras GAP (residues 32 to $40[33,41]$ ) and Ras GEF (residues $62,63,67$, and 75 to $78[25,38,42,51])$, it may also share functional similarities with Ras proteins. Therefore, we have evaluated the transforming potential of wild-type and putative constitutively activated forms of TC21. We observed that mutant TC21 proteins displayed surprisingly potent transforming activities which were comparable to those of oncogenic Ras proteins. These results identify TC21 as the first Ras-related protein with potent transforming activity and support the possibility that aberrant TC21 function plays an important role in human carcinogenesis.

\section{MATERIALS AND METHODS}

Generation of TC21 mutants and molecular constructs. Oligonucleotide-directed mutagenesis was used to generate mutant TC21 sequences encoding proteins with single amino acid substitutions at residues that correspond to analogous mutations that activate Ras transforming activity (2). All mutant sequences were generated in a 2.0 -kb EcoRI fragment that contains the TC21 cDNA sequence (19). TC21(22V/71L) contains Gly (GGC)-to-Val (GTC) and Gln (CAA)-to-Leu (CTA) mutations at the positions that correspond to Ras residues 12 and 61 , respectively. TC21(45A/71L) contains a $\mathrm{Thr}(\underline{\mathrm{ACC}})$-to-Ala (GCC) mutation at the position that corresponds to residue 35 in the Ras effector domain. Single (22V) and (71L) TC21 mutant sequences were generated by restriction digest of the double mutant TC21 $(22 \mathrm{~V} / 71 \mathrm{~L})$ with the restriction enzyme $H h a I$. This separated the mutant sequence into an N-terminal $0.1-\mathrm{kb}$ fragment containing the $22 \mathrm{~V}$ mutation (encoding residues 1 to 27 ) and a C-terminal $1.9-\mathrm{kb}$ fragment containing the $71 \mathrm{~L}$ mutation (encoding residues 28 to 189), which were then ligated with the appropriate wild-type fragments to generate a full-length sequence. Each mutant $T C 21$ sequence was then introduced into the unique $E c o$ RI site of a modified pZIP-NeoSV(X)1 retrovirus vector (12). All mutated sequences were subsequently verified by dideoxy sequencing using the Sequenase II kit as instructed by the manufacturer (U.S. Biochemical Corp.).

Cell culture and transformation assays. NIH 3T3 and Rat-1 cells were grown in Dulbecco's modified Eagle's medium supplemented with either $10 \%$ calf serum (NIH 3T3) or $10 \%$ fetal calf serum (Rat-1). DNA transfections were done as previously described, using the calcium phosphate precipitation technique (11). Cells were transfected with, per dish, $10 \mathrm{ng}$ (NIH 3T3) or $2 \mu \mathrm{g}$ (Rat-1) of pZIP plasmid DNAs encoding normal or mutant TC21 or Ras protein. Transformed foci were quantitated after 14 days (NIH 3T3) or 22 days (Rat-1). Rat-1 cultures were stained with $0.4 \%$ crystal violet to better visualize transformed foci. Transfected cells were also selected in growth medium containing G418 (Geneticin; GIBCO/BRL) at $400 \mu \mathrm{g} / \mathrm{ml}$ to establish cell lines that stably expressed normal or mutant proteins. The growth properties of NIH 3T3 cells expressing TC21 and Ras proteins were compared, using low-serum $(0.5$ to $2 \%)$, soft agar $(0.3 \%)$, and nude mouse tumorigenicity $\left(5 \times 10^{5}\right.$ cells per site) assays as described previously (17).

MAPK and transcriptional activation assays. Activation of mitogen-activated protein kinases (MAPKs) in NIH 3 T3 cells expressing TC21 or Ras protein was determined as described previously (55). Briefly, total cell extracts were resolved by sodium dodecyl sulfate-polyacrylamide gel electrophoresis (SDS-PAGE) and then transferred to Immobilon membranes (Millipore) for analysis by Western blotting (immunoblotting using the rabbit anti-ERK antiserum 691 (Santa Cruz Biotechnology, Santa Cruz, Calif.) to detect phosphorylated, activated forms of both $\mathrm{p} 42^{\mathrm{MAPK}} / \mathrm{ERK} 2$ and $\mathrm{p} 44^{\mathrm{MAPK}} / \mathrm{ERK} 1$.

To determine the ability of TC21 to induce transcriptional activation, NIH 3T3 cells were transiently cotransfected with 2 to $5 \mu \mathrm{g}$ of pZIP DNA encoding normal or mutant TC21 protein (or $100 \mathrm{ng}$ of ras controls) together with $1 \mu \mathrm{g}$ of one of two different chloramphenicol acetyltransferase (CAT) reporter plasmids driven by minimal promoter sequences that contain Ras-responsive elements (RREs). pB4X-CAT contains four tandem copies of the RRE from the polyomavirus enhancer (Ets/AP-1 sequences) (provided by B. Wasylyk) (54), whereas MHC WT CAT contains three tandem repeats of the major histocompatibility complex class I enhancer element NF-kB (provided by A. Baldwin) (3). Forty-eight hours after transfection, cell lysates were prepared, and the CAT activity induced by each pZIP-TC21 or pZIP-ras construct was assayed as described previously $(14,24)$.

Prenylation analysis of TC21 protein. A $2.0-\mathrm{kb} E c o R I$ fragment containing the TC21 coding sequence was ligated into the EcoRI site of the pAcC13 transfer vector, and recombinant baculovirus was isolated by procedures described previously (10). Spodoptera frugiperda (Sf9) insect cells were infected with the TC21 baculovirus as described previously (10) and labeled overnight in ExCell 401 growth medium (JRH Biologicals) supplemented with either $\left[{ }^{35} \mathrm{~S}\right]$ methionine-cysteine $\left[{ }^{35}\right.$ S]Met-Cys; Tran ${ }^{35} \mathrm{~S}-$ label; $200 \mu \mathrm{Ci} / \mathrm{ml}$; ICN) or [5- $\left.{ }^{3} \mathrm{H}\right]$ mevalonolactone $(200 \mu \mathrm{Ci} / \mathrm{ml}$; DuPont-NEN $)$, which is converted in vivo to mevalonic acid (MVA), the precursor of isoprenoid groups. Metabolic labeling was also done in the presence of compactin, an inhibitor of all isoprenoid biosynthesis (16). For fractionation analysis, labeled cells were separated into crude membrane (P100)- and cytosolic (S100)containing fractions by centrifugation $(100,000 \times g, 30 \mathrm{~min})$ as described previously (11). Labeled TC21 proteins were immunoprecipitated from each fraction by using mouse monoclonal antibody 142-24E5 (generated against amino acids 96 to 118 of Ras; recognizes Ras, Rap, and other Ras-related proteins; (Quality Biotech, Camden, N.J.), resolved by SDS-PAGE, and subjected to fluorographic analysis.

\section{RESULTS}

Mutant forms of TC21 exhibit potent morphologic transformation of NIH $3 T 3$ and Rat-1 cells. To determine whether TC21 possesses transforming potential, we generated mutant forms of TC21 with substitutions analogous to those present in oncogenic Ras proteins (Table 1). TC21(22V) contains a Gly-to-Val substitution analogous to the residue 12 mutation in Ras, TC21(71L) contains a Gln-to-Leu substitution analogous to the residue 61 mutation in Ras, and TC21(22V/71L) contains both mutations. When introduced into Ras proteins, each of these mutations results in chronically active, GTPbound mutant proteins that exhibit potent oncogenic activity. The transforming potential of each of these TC21 mutant proteins was then compared with that of oncogenic Ras proteins in NIH 3T3 and Rat-1 cell transformation assays.

Whereas transfection of up to $2 \mu \mathrm{g}$ of pZIP-TC21(WT) DNA caused no focus-forming activity, transfection with only $10 \mathrm{ng}$ of each mutant $T C 21 \mathrm{pZIP}$ plasmid DNA $(22 \mathrm{~V}, 71 \mathrm{~L}$, and 
TABLE 1. Biological properties of TC21 and Ras proteins

\begin{tabular}{|c|c|c|c|c|c|}
\hline \multirow{2}{*}{ Protein } & \multicolumn{4}{|c|}{ NIH 3T3 } & \multirow{2}{*}{ Rat-1 foci ${ }^{a}$} \\
\hline & $\overline{\text { Foci }^{b}}$ & Agar & Serum $^{d}$ & $\overline{\text { Mice }^{e}}$ & \\
\hline \multicolumn{6}{|l|}{ Ras } \\
\hline Wild type & 0.00 & - & - & 0 & - \\
\hline $61 \mathrm{~L}$ & 1.00 & +++ & ++ & 3 & ++ \\
\hline \multicolumn{6}{|l|}{ TC21 } \\
\hline Wild type & 0.00 & - & - & $0^{f}$ & - \\
\hline $22 \mathrm{~V}$ & 1.04 & +++ & ++ & 3 & + \\
\hline $71 \mathrm{~L}$ & 1.17 & +++ & ++ & 3 & ++ \\
\hline $22 \mathrm{~V} / 71 \mathrm{~L}$ & 1.19 & +++ & ++ & 3 & ++ \\
\hline $45 \mathrm{~A} / 71 \mathrm{~L}$ & 0.00 & - & - & 0 & - \\
\hline Vector only & 0.00 & ND & - & 0 & - \\
\hline
\end{tabular}

${ }^{a}$ Appearance of transformed foci on monolayer cultures (see also Fig. 1).

${ }^{b}$ Relative focus-forming activity; all values were normalized to the activity observed for Ras(61L) $\left(4 \times 10^{3}\right.$ to $7 \times 10^{3}$ foci per $\mu \mathrm{g}$ of transfected DNA). All pZIP plasmid DNAs were transfected at $10 \mathrm{ng}$ per 60 -mm-diameter dish except pZIP-TC21(WT), which was transfected at 10 to $2,000 \mathrm{ng}$ per dish. Whereas transfection of pZIP-ras (WT) at high plasmid concentrations ( $>500 \mathrm{ng}$ per dish) will result in low focus-forming activity, no focus-forming activity was observed for pZIP-TC21(WT) at up to $2 \mu \mathrm{g}$ of plasmid DNA per dish. Values represent averages from at least three separate experiments done in quadruplicate.

${ }^{c}$ Colony formation in soft agar. ND, not determined.

${ }^{d}$ Growth in $0.5 \%$ calf serum.

${ }^{e}$ Number of animals positive for tumor formation out of three animals inoculated $\left(5 \times 10^{5}\right.$ cells per site).

${ }^{f}$ In contrast to the very large and progressively growing tumors associated with animals injected with Ras- or TC21-transformed cells, the animals in this group were negative for tumor growth at 2 weeks; however, tumor growth was observed at approximately 4 weeks.

22V/71L) per dish caused significant focus-forming activity (4 $\times 10^{3}$ to $7 \times 10^{3}$ foci per $\mu$ g of DNA) comparable to the activity seen with oncogenic pZIP-ras(61L) (Table 1). Transfection of Rat-1 cells showed similar results, with each TC21 mutant inducing levels of transformed foci that were equivalent to those induced by oncogenic $\operatorname{Ras}(61 \mathrm{~L})$ (Fig. 1). Like wild-type Ras, wild-type TC21 was completely negative for focus-forming activity in transfected Rat-1 cells.

The Ras effector domain (residues 32 to 40 ) is required for Ras interaction with its putative downstream targets, p120 and NF1 GAP $(33,41)$ and the Raf-1 serine/threonine kinase (36,

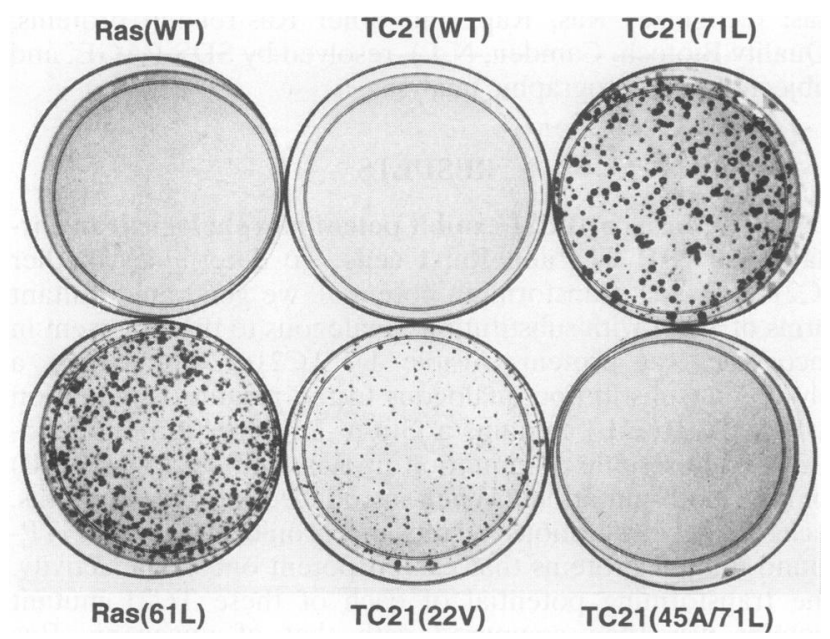

FIG. 1. TC21-induced focus formation in transfected Rat-1 cells. Rat-1 cells were transfected with $2 \mu \mathrm{g}$ of pZIP-TC21 plasmid DNA for expression of each TC21 protein. Transformed foci were visualized after 22 days by staining with crystal violet. WT, wild type.
$50,52,53)$, and mutations at those residues that perturb effector binding result in the complete loss of Ras transforming activity. Since these residues are identical in TC21, we determined whether this region is also critical for TC21 transforming activity. Therefore, a Thr-to-Ala mutation was introduced at residue 45 of $\mathrm{TC} 21$ (analogous to Ras residue 35) to generate the TC21 (45A/71L) mutant protein. The complete loss of transforming activity of this mutant protein suggests that this region may also function as the effector domain of TC21 (Table 1 and Fig. 1).

Although mutant versions of both TC21 and Ras proteins induced comparable levels of transformed foci, their appearance could be readily distinguished in transfected NIH 3T3 cultures. Whereas Ras-induced foci are typically swirling, spreading colonies of transformed cells, TC21-induced foci contained clumps of cells that tended to round up and pull away from the plastic substratum (Fig. 2A). However, the expression of wild-type and mutant TC21 induced alterations in the morphology of individual cells that were similar to those of their Ras counterparts. NIH 3T3 cells stably transfected with the wild-type form of either Ras (data not shown) or TC21 displayed morphologies that were indistinguishable from the very flat, nonrefractile morphology of untransformed NIH 3T3 cells, whereas mutant TC21 proteins induced transformed morphologies that were similar to the spindle-shaped, elongated, and very refractile appearance of Ras-transformed cells (Fig. 2B).

Mutated TC21 proteins induce altered growth characteristics. To further evaluate the consequences of mutant TC21 expression on NIH 3T3 cells, we compared the growth properties of TC21- and Ras-transformed cells. To determine if mutant TC21 expression triggered anchorage-independent growth, NIH 3T3 cells stably expressing wild-type or mutant forms of TC21 were plated in soft agar and assayed for the ability to form colonies. Like Ras-transformed cells (data not shown), TC21(22V)- and TC21(71L)-transformed cells readily formed colonies in soft agar (Fig. 2C). In contrast, cells expressing the wild-type form of Ras (data not shown) or TC21, or the TC21(45A/71L) effector domain mutant, failed to grow under these conditions (Fig. 2C).

We also analyzed the ability of TC21(22V)- and TC21(71L)transformed cells to proliferate in growth medium supplemented with low serum. Whereas the growth of NIH 3T3 cells stably expressing wild-type Ras or TC21 was significantly diminished in culture medium supplemented with $2 \%$ calf serum, both Ras- and TC21-transformed cells continued to proliferate in culture medium supplemented with as little as $0.5 \%$ calf serum (Fig. 3 ).

Finally, we evaluated the ability of TC21-transformed NIH 3T3 cells to form tumors in athymic nude mice. As with Ras-transformed cells, subcutaneous injection of $5 \times 10^{5}$ TC21-transformed cells per site induced rapid tumor development within less than 2 weeks. Interestingly, we observed that TC21-transformed cells induced an even more rapid and aggressive tumor development than Ras-transformed cells, with TC21-induced tumors more than double the size of the tumors induced by Ras-transformed cells (Table 1). Finally, while NIH 3T3 cells stably expressing wild-type Ras or TC21 showed significantly reduced abilities to induce tumor formation, the wild-type TC21-expressing cells formed progressive tumors after approximately 4 weeks, whereas NIH 3T3 cells that were transfected with the pZIP vector control or with the effector mutant TC21(45A/71L) were negative for tumor formation even after 3 months. Thus, wild-type TC21 may also cause malignant transformation, presumably as a result of elevated levels of expression. The greatly elevated levels of 
A

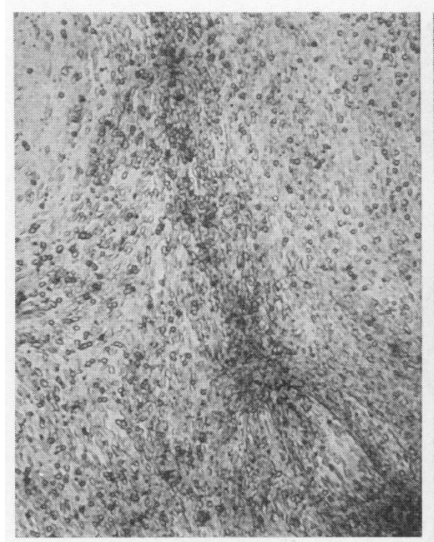

$\operatorname{Ras}(61 \mathrm{~L})$

B

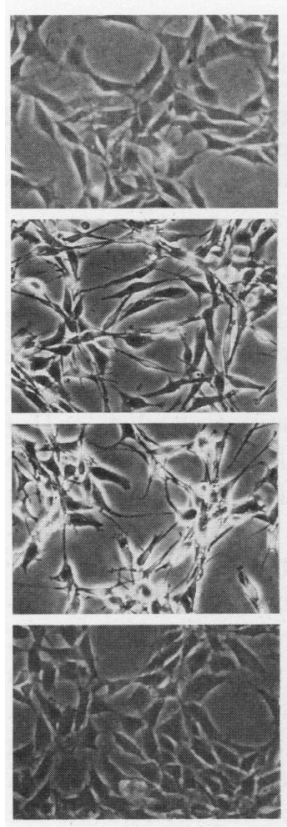

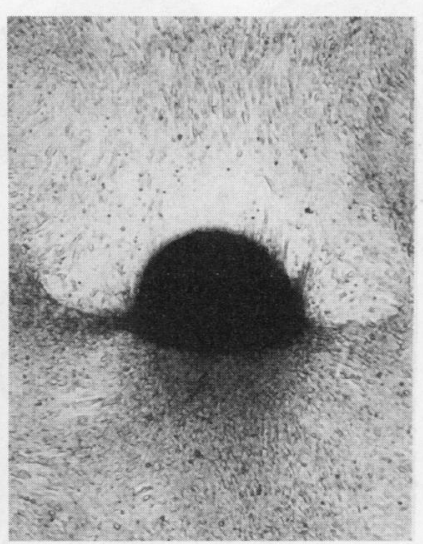

TC21(71L)

C

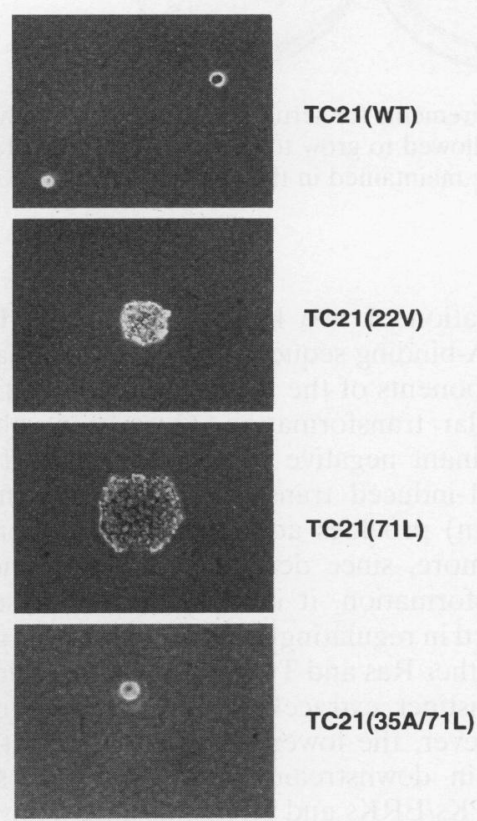

FIG. 2. Transformed growth properties of TC21-transformed cells. (A) Mutants $\operatorname{Ras}(61 \mathrm{~L})$ and TC21(71L) induced the appearance of distinctly different transformed foci in transfected NIH 3T3 cultures. (B) NIH 3T3 cells were transfected with the indicated pZIP-TC21 plasmid DNA and selected in G418-containing growth medium. (C) Single-cell suspensions of G418-selected NIH 3T3 cells expressing the indicated TC21 protein were plated in agar at a density of $10^{2}$ or $10^{3}$ cells per 60 -mm-diameter dish, and colony formation was scored after 2 weeks. WT, wild type.

wild-type TC21 protein expressed in tumor-reconstituted cells support this possibility (data not shown). Altogether, these results demonstrate that TC21-transformed cells possess the same aberrant growth properties as Ras-transformed cells.

p42 ${ }^{\mathrm{MAPK}} / \mathrm{ERK} 2$ and $\mathrm{p44}{ }^{\mathrm{MAPK}} / \mathrm{ERK} 1$ are constitutively activated in TC21-transformed cells. In Ras-transformed NIH 3T3 cells, some downstream signaling elements, including $\mathrm{p} 42^{\mathrm{MAPK}} / \mathrm{ERK} 2$ and $\mathrm{p} 44^{\mathrm{MAPK}} / \mathrm{ERK} 1$, are constitutively activated $(5,18)$. Therefore, we analyzed the electrophoretic profiles of MAPKs in TC21-transformed NIH 3T3 cells. Like
Ras-transformed cells, TC21(71L)-transformed NIH 3T3 cells showed enhanced levels of the phosphorylated, activated forms of both $\mathrm{p}^{\mathrm{MAPK}} / \mathrm{ERK} 2$ and $\mathrm{p} 44^{\mathrm{MAPK}} / \mathrm{ERK} 1$ (Fig. 4). In contrast, only the nonphosphorylated, inactive forms of MAPKs were detected in NIH 3T3 cells stably expressing the wild-type form of either Ras or TC21 (Fig. 4). Thus, TC21induced cellular transformation is also associated with constitutive activation of MAPKs in NIH 3T3 cells.

Mutant forms of TC21 can activate transcription from RREs. Oncogenic, but not wild-type, Ras proteins can induce high levels of transcriptional activation from promoters containing RREs (24). To determine if the transforming versions of TC21 trigger similar downstream events, we performed transcriptional activation assays using CAT reporter plasmids containing the Ets/AP-1 and NFKB RREs from the polyomavirus (54) and major histocompatibility class I (3) enhancer elements, respectively.

Like wild-type Ras, wild-type TC21 did not appreciably cause transcriptional activation from reporter plasmids containing either RRE (Fig. 5). In contrast, both TC21(22V) and TC21(71L) potently caused transactivation of the RRE from the $\kappa \mathrm{B}$ element (Fig. 5A) and the polyomavirus enhancer (Fig. $5 B)$. The introduction of the effector domain mutation into TC21 abolished the ability of TC21(45A/71L) to induce transactivation in each assay, implying the importance of an intact effector domain for perpetuating the transcriptional activation signal. While the precise signal transduction pathways that mediate Ras-induced transcription activation from the different RREs are not completely known (18), the ability of mutant TC21 proteins to induce the activation of the same targets suggest that Ras and TC21 may trigger some common downstream signaling events.

TC21 is isoprenylated and membrane associated. The importance of prenylation and membrane association for Ras transforming activity has been well documented (16). The carboxyl terminus of TC21 is similar to that of the membranetargeting sequence at the carboxyl terminus of Ras proteins in that it contains a polybasic domain, a putative palmitylated cysteine, and a prenylation signal sequence (16). Therefore, we determined whether TC21 is also prenylated and membrane associated. Sf9 insect cells infected with wild-type TC21 baculovirus were efficiently labeled with $\left[{ }^{3} \mathrm{H}\right] \mathrm{MVA}$, and the labeled TC21 protein fractionated exclusively to the membrane fraction (Fig. 6). Fractionation analysis of $\left[{ }^{35} \mathrm{~S}\right] \mathrm{Met}-\mathrm{Cys}-\mathrm{labeled}$ Sf 9 cells showed that the majority of TC21 was present as a membrane-associated band which comigrated with the $\left[{ }^{3} \mathrm{H}\right] \mathrm{MVA}$-labeled band, and a minority was present as a cytosolic band which exhibited a reduced electrophoretic mobility. In compactin-treated cells, TC21 was present exclusively in the cytosolic, more slowly migrating form (data not shown). These results are similar to our previous observations of Ras and Ras-related proteins overexpressed in insect cells, in which prenylation increases electrophoretic mobility and a mixture of prenylated and nonprenylated proteins are present $(10,28)$. Thus, like Ras and other Ras-related proteins, TC21 undergoes a prenylation-dependent translocation to membranes.

\section{DISCUSSION}

Although Ras-related proteins share significant structural and biochemical similarities with Ras proteins, to date none has been found to possess the same oncogenic potential as the four Ras proteins $(6,27)$. In particular, no transforming potential has yet been ascribed to any of the Ras-related proteins that have greater than $50 \%$ amino acid identity with Ras proteins (Ral, Rap, and R-Ras). For example, overexpres- 


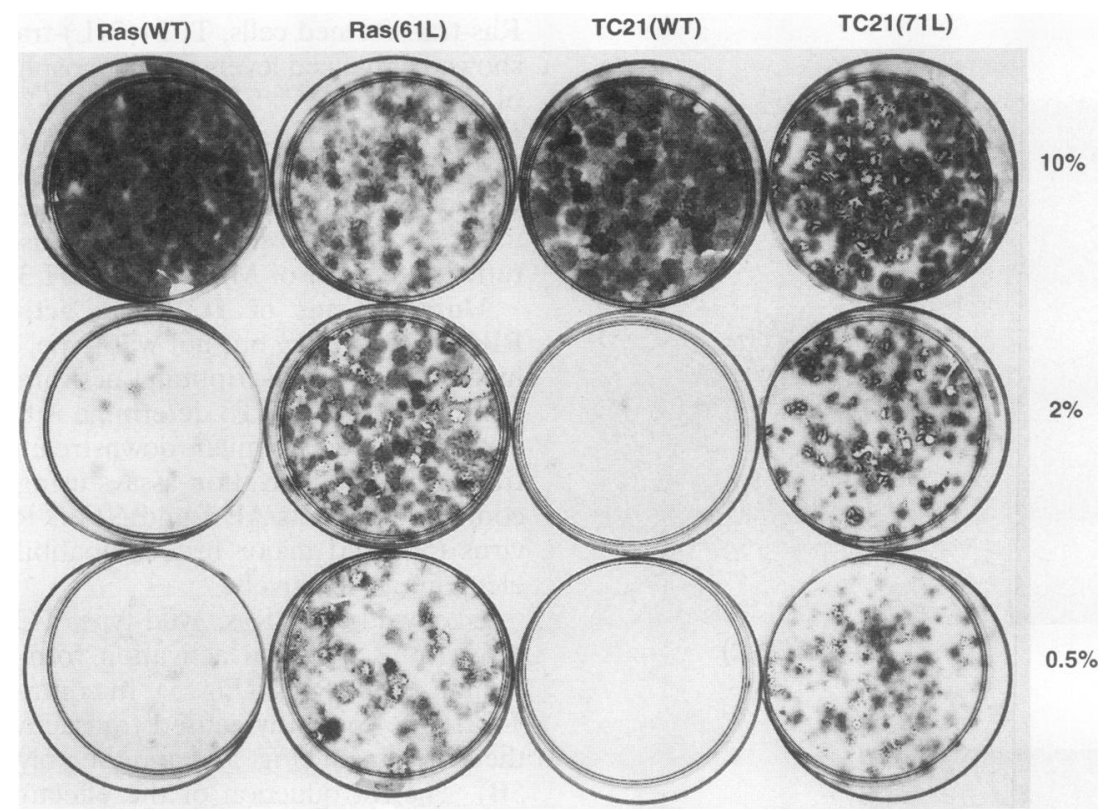

FIG. 3. NIH 3T3 cells expressing mutant TC21 proteins display reduced requirements for serum. NIH 3 T3 cells stably expressing the indicated TC21 proteins were plated at a density of $10^{3}$ cells per 60 - $\mathrm{mm}$-diameter dish, allowed to grow for $24 \mathrm{~h}$ in $10 \%$ calf serum, and then changed to growth medium supplemented with $0.5,2$, or $10 \%$ calf serum. The cultures were maintained in the designated serum concentrations for 2 weeks and then stained with crystal violet to visualize cells. WT, wild type.

sion of wild-type Krev-1/Rap1a protein was found to block Ras-transforming activity (30), and the introduction of putative oncogenic mutations into Krev-1 served only to potentiate this suppressing activity, rather than to endow Krev-1 with transforming activity (29). Consequently, we were surprised to find that mutant forms of TC21/R-Ras2 that harbor mutations analogous to those that cause potent activation of Ras transforming potential possess the same ability to trigger the malignant transformation of rodent fibroblast cells. We observed that, like Ras-transformed cells, TC21-transformed cells proliferated in soft agar and in low serum and formed tumors in nude mice. Thus, TC21 represents the first Rasrelated protein that possesses potent transforming activities which are comparable to those of oncogenic forms of Ras.

Many components of the Ras signal transduction pathway have recently been defined $(5,6,18,20,27,35)$. Since we observed that transforming versions of TC21, like oncogenic Ras, stimulated the constitutive activation of both $\mathrm{p} 42^{\mathrm{MAPK}} /$ ERK2 and p44 ${ }^{\mathrm{MAPK}} / \mathrm{ERK} 1$, as well as the transcriptional

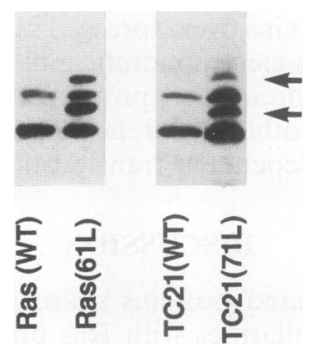

FIG. 4. Activation of MAPK in TC21-transformed cells. NIH 3T3 cells stably expressing wild-type (WT) and mutant Ras and TC21 proteins were analyzed by SDS-PAGE and Western blot analysis for phosphorylation or activation of $\mathrm{p} 42^{\mathrm{MAPK}} / \mathrm{ERK} 2$ and $\mathrm{p} 44^{\mathrm{MAPK}} / \mathrm{ERK} 1$. The phosphorylated, activated forms are designated by arrows. activation of two known RREs (the ETs/AP-1 and NF-kB DNA-binding sequences) (24), TC21 may utilize at least some components of the Ras signal transduction pathway to trigger cellular transformation. Our recent observation that a Raf dominant negative protein (designated Raf301) blocks both TC21-induced transactivation and transformation (data not shown) provides additional support for this possibility. Furthermore, since deregulated TC21 function triggers cellular transformation, it is reasonable to assume that TC21 is involved in regulating some aspects of the growth of normal cells. Whether Ras and TC21 are stimulated in response to common or distinct extracellular signals remains to be determined. However, the lower potency of TC21 than Ras in triggering certain downstream signaling events such as activation of MAPKs/ERKs and RREs, despite equivalent potencies in the transformation assays, coupled with the strikingly different appearance of the transformed foci, suggests the possibility that the overlap in signaling pathways is only partial and that some TC21-specific components remain to be identified.

Finally, since TC21 shares complete identity with Ras residues important for regulation by Ras GAPs and Raf-1 (residues 32 to $40[33,41]$ ) and Ras GEFs (residues 62, 63, 67, 69, and 75 to $78[25,38,42,51])$, there is a strong possibility that the TC21 GDP/GTP cycle may be controlled at least in part by regulators of the Ras GDP/GTP cycle. In support of this possibility, we observed that a mutation in the region of TC21 which is identical to the Ras effector domain (residues 32 to 40) completely abolishes TC21 transforming activity. Whether TC21 interacts with Ras GAPs and/or Raf-1, or with its own effector target(s), remains to be determined. Finally, we have recently observed that Ras GEFs (SOS1 and CDC25/GRF) activate the transforming potential of wild-type TC21 (22a), indicating that at least some regulators of Ras function may also control TC21 function.

Our observation that TC21 exhibits potent transforming activity is surprising in light of previous studies of the closely 

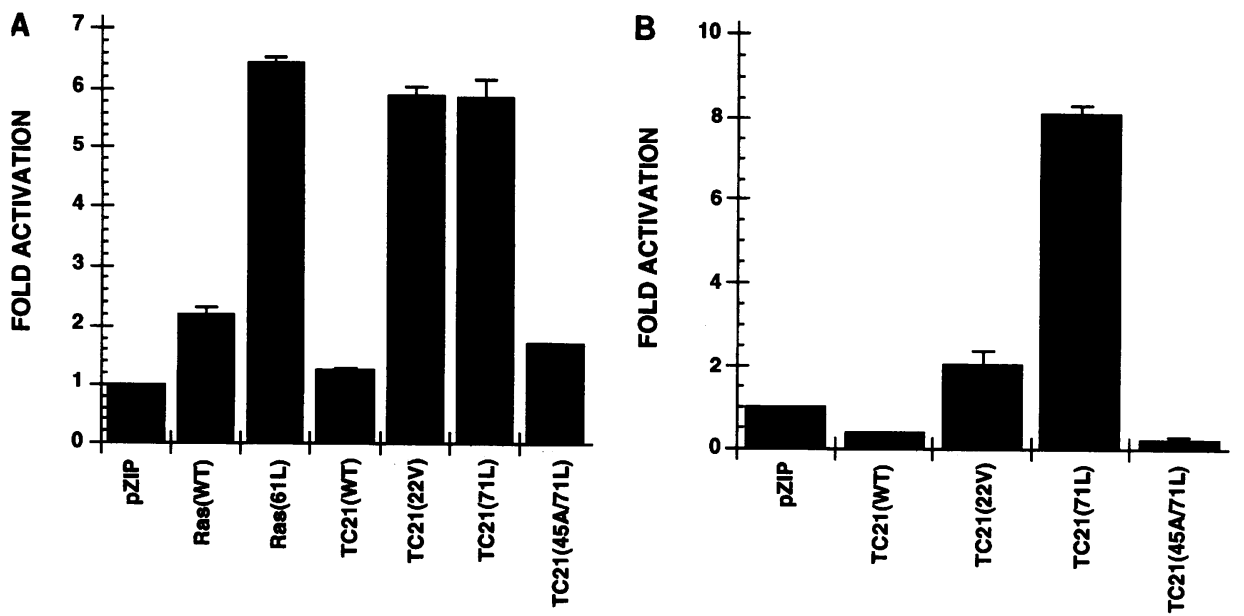

FIG. 5. TC21-induced transcriptional activation from RREs. Transient transfection analysis was used to assess the ability of each wild-type (WT) or mutant TC21 protein to activate transcription from either the MHC WT CAT (A) or pB4X-CAT (B) reporter plasmid. We consistently observed that significantly more pZIP-TC21 plasmid DNA $(5 \mu \mathrm{g})$ was required to achieve the same levels of stimulation observed with pZIP-ras(61L) ( 2 or $0.1 \mu \mathrm{g}$ per dish for the MHC WT CAT or pB4X-CAT assay, respectively). Results are representative of at least three independent experiments performed in duplicate.

related R-Ras protein. R-Ras shares $\sim 70 \%$ amino acid identity with TC21 (19). Like TC21, R-Ras also shares identity with residues in Ras that are important for Ras GAP and GEF stimulation. Furthermore, R-Ras can interact with the Raf-1 serine/threonine kinase (44), which is believed to be the critical downstream target for Ras activity $(36,50,52,53,56)$. Despite this high homology to Ras and TC21, a 12V version of R-Ras lacked any detectable transforming activity in Rat-1 cells (32). We can envision at least three possible explanations for the previously described lack of R-Ras transforming activity. First, the R-Ras transformation studies utilized Rat-1 cells, but not NIH 3 T3 cells, and the pathways for transformation in these cells are at least partially distinct $(23,45)$. We have observed that mutant R-Ras proteins show transforming activity in NIH 3 T3 cells but not in Rat-1 cells (15a), although the properties of R-Ras-transformed cells are distinct from those transformed by mutant TC21/R-Ras 2 or Ras. Second, we have found that TC21(22V) consistently showed weaker transforming and transactivation activities than TC21(71L). Thus, a $61 \mathrm{~L}$ version of R-Ras may exhibit greater transforming potential than the $12 \mathrm{~V}$ version previously tested. Lastly, a recent study has shown that R-Ras associates with Bcl-2, an antagonist of apoptotic cell death, via sequences contained in the carboxylterminal 60 amino acids of R-Ras (21). Since TC21 and R-Ras show the greatest sequence divergence at their carboxyl ter-

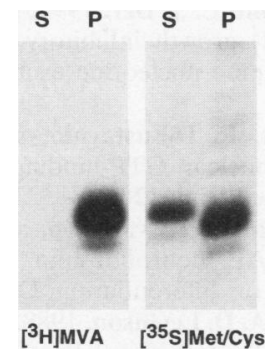

FIG. 6. TC21 protein is prenylated and membrane associated. $T C 21$ baculovirus-infected Sf 9 cells were radiolabeled with either $\left[{ }^{3} \mathrm{H}\right] \mathrm{MVA}$ or $\left[{ }^{35} \mathrm{~S}\right] \mathrm{Met}-\mathrm{Cys}$ and fractionated into crude cytosolic (S) or membrane (P) fractions as described in Materials and Methods. mini, the possibility that $\mathrm{TC} 21$ does not associate with $\mathrm{Bcl}-2$ may account for the different activities observed in these two highly related proteins. Using the yeast two-hybrid approach, we are presently determining whether TC21 can associate with Bcl-2.

In light of our demonstration that mutant versions of TC21 show potent transforming activities in rodent fibroblast cells, it is perhaps surprising that activated forms of TC21 have not been identified in human cancers to date. One possible reason for this may be the different patterns of expression of TC21 and Ras proteins. Whereas Ras proteins are ubiquitously expressed, a limited analysis of a variety of cell lines suggested that TC21 may be preferentially expressed in certain cell types, such as kidney-derived cells (19). We are presently comparing the levels of expression of TC21 and Ras proteins in a panel of tissue types to extend these observations. A second possible reason for the lack of detection of activated forms of TC21 in human tumors to date may be that the majority of tumor analyses have been carried out with Ras-specific oligonucleotides, which would not recognize TC21 sequences. Therefore, we are presently using TC21-specific oligonucleotides to screen human tumors for mutations in this ras-related gene.

Like Ras, TC21 is prenylated and membrane associated, and it is likely that, as for Ras, these properties are necessary for TC21 transforming activity. Therefore, if TC21 is found to contribute to human cancers, such tumors would be good candidates for treatment with prenylation inhibitors such as the CAAX-based peptidomimetic compounds that have recently been shown to be powerful and specific inhibitors of the growth of Ras-transformed cells in vitro $(22,26,31)$.

\section{ACKNOWLEDGMENTS}

We thank Leah Conroy (Chiron) for assistance in the generation of the TC21 recombinant baculovirus, Al Baldwin (UNC-Chapel Hill) for providing the MHC WT CAT reporter plasmid, Alan Hall for communicating data prior to publication, and Ronda Gwynn for excellent secretarial assistance.

This work was supported by grants from the National Institutes of Health to C.J.D. (CA42978, CA52072, and CA55008) and from the American Cancer Society to M.G.R. (CB100). C.J.D. is the recipient of an American Cancer Society Faculty Research Award. 


\section{REFERENCES}

1. Avraham, H., and R. A. Weinberg. 1989. Characterization and expression of the human rhoH12 gene product. Mol. Cell. Biol. 9:2058-2066.

2. Barbacid, M. 1987. ras genes. Annu. Rev. Biochem. 56:779-827.

3. Beg, A. A., S. M. Ruben, R. I. Scheinman, S. Haskill, C. A. Rosen, and A. S. Baldwin, Jr. 1992. IкB interacts with the nuclear localization sequences of the subunits of NF- $\mathrm{kB}$ : a mechanism for cytoplasmic retention. Genes Dev. 6:1899-1913.

4. Belhumeur, P., A. Lee, R. Tam, T. Dipaolo, N. Fortin, and M. W. Clark. 1993. GSP1 and GSP2, genetic suppressors of the prp20-1 mutant in Saccharomyces cerevisiae: GTP-binding proteins involved in the maintenance of nuclear organization. Mol. Cell. Biol. 13:2152-2161.

5. Blenis, J. 1993. Signal transduction via the MAP kinases: proceed at your own RSK. Proc. Natl. Acad. Sci. USA 90:5889-5892.

6. Bokoch, G. M., and C. J. Der. 1993. Emerging concepts in the Ras superfamily of GTP-binding proteins. FASEB J. 7:750-759.

7. Bollag, G., and F. McCormick. 1992. GTPase activating proteins. Cancer Biol. 3:199-208.

8. Bos, J. L. 1989. ras oncogenes in human cancer: a review. Cancer Res. 49:4682-4689.

9. Bourne, H. R., D. A. Sanders, and F. McCormick. 1990. The GTPase superfamily: conserved structure and molecular mechanism. Nature (London) 349:117-126.

10. Buss, J. E., L. A. Quilliam, K. Kato, P. J. Casey, P. A. Solski, G. Wong, R. Clark, F. McCormick, G. M. Bokoch, and C. J. Der. 1991. The COOH-terminal domain of the Rap1A (Krev-1) protein is isoprenylated and supports transformation by an H-Ras:Rap1A chimeric protein. Mol. Cell. Biol. 11:1523-1530.

11. Buss, J. E., P. A. Solski, J. P. Schaeffer, M. J. MacDonald, and C. J. Der. 1989. Activation of the cellular proto-oncogene product p21Ras by addition of a myristylation signal. Science 243:16001603.

12. Cepko, C. L., B. Roberts, and R. C. Mulligan. 1984. Construction and applications of a highly transmissible murine retrovirus shuttle vector. Cell 37:1053-1062.

13. Clark, G. J., and C. J. Der. 1992. Oncogenic activation of Ras proteins, p. 258-287. In B. F. Dickey and L. Birnbaumer (ed.), Handbook of experimental pharmacology, vol. 1. GTPases in biology. Springer-Verlag, Heidelberg.

14. Clark, G. J., L. A. Quilliam, M. M. Hisaka, and C. J. Der. 1993. Differential antagonism of Ras biological activity by catalytic and Src homology domains of Ras GTPase activation protein. Proc. Natl. Acad. Sci. USA 90:4887-4891.

15. Cook, S. J., B. Rubinfeld, I. Albert, and F. McCormick. 1993. RapV12 antagonizes Ras-dependent activation of ERK1 and ERK2 by LPA and EGF in Rat-1 fibroblasts. EMBO J. 12:34753485 .

15a.Cox, A. D., et al. Unpublished data.

16. Cox, A. D., and C. J. Der. 1992. Protein prenylation: more than just glue? Curr. Opin. Cell Biol. 4:1008-1016.

17. Cox, A. D., and C. J. Der. 1994. Biological assays for cellular transformation. Methods Enzymol. 238:277-294.

18. Davis, R. J. 1993. The mitogen-activated protein kinase signal transduction pathway. J. Biol. Chem. 268:14553-14556.

19. Drivas, G. T., A. Shih, E. Coutavas, M. G. Rush, and $\mathbf{P}$. D'Eustachio. 1990. Characterization of four novel ras-like genes expressed in a human teratocarcinoma cell line. Mol. Cell. Biol. 10:1793-1798

20. Feig, L. A. 1993. The many roads that lead to Ras. Science 260:767-768.

21. Fernandez-Sarabia, M. J., and J. R. Bischoff. 1993. Bcl-2 associates with the ras-related protein R-ras p23. Nature (London) 366:274-275.

22. Garcia, A. M., C. Rowell, K. Ackermann, J. J. Kowalczyk, and M. D. Lewis. 1993. Peptidomimetic inhibitors of Ras farnesylation and function in whole cells. J. Biol. Chem. 268:18415-18418.

22a.Graham, S. M., et al. Unpublished data.

23. Gupta, S. K., C. Gallego, J. M. Lowndes, C. M. Pleiman, C. Sable, B. J. Eisfelder, and G. L. Johnson. 1992. Analysis of the fibroblast transformation potential of GTPase-deficient gip2 oncogenes. Mol. Cell. Biol. 12:190-197.
24. Hauser, C. A., C. J. Der, and A. D. Cox. 1994. Transcriptional activation and oncogene function. Methods Enzymol. 238:271276.

25. Howe, L. R., and C. J. Marshall. 1993. Identification of amino acids in p21ras involved in exchange factor interaction. Oncogene 8:2583-2590.

26. James, G. L., J. L. Goldstein, M. S. Brown, T. E. Rawson, T. C. Somers, R. S. McDowell, C. W. Crowley, B. K. Lucas, A. D. Levinson, and J. C. Marsters, Jr. 1993. Benzodiazepine peptidomimetics: potent inhibitors of Ras farnesylation in animal cells. Science 260:1937-1942.

27. Khosravi-Far, R., and C. J. Der. 1994. The Ras signal transduction pathway. Cancer Metastasis Rev. 13:67-89.

28. Khosravi-Far, R., R. J. Lutz, A. D. Cox, L. Conroy, J. R. Bourne, M. Sinensky, W. E. Balch, J. E. Buss, and C. J. Der. 1991. Isoprenoid modification of rab proteins terminating in $\mathrm{CC} / \mathrm{CXC}$ motifs. Proc. Natl. Acad. Sci. USA 88:6264-6268.

29. Kitayama, H., T. Matsuzaki, Y. Ikawa, and M. Noda. 1990. Genetic analysis of the Kirsten-ras-revertant 1 gene: potentiation of its tumor suppressor activity by specific point mutations. Proc. Natl. Acad. Sci. USA 87:4284-4288.

30. Kitayama, H., Y. Sugimoto, T. Matsuzaki, Y. Ikawa, and M. Noda. 1989. A ras-related gene with transformation suppressor activity. Cell 56:77-84.

31. Kohl, N. E., S. D. Mosser, S. J. deSolms, E. A. Giuliani, D. L. Pompliano, S. L. Graham, R. L. Smith, E. M. Scolnick, A. Oliff, and J. B. Gibbs. 1993. Selective inhibition of ras-dependent transformation by a farnesyltransferase inhibitor. Science 260: 1934-1937.

32. Lowe, D. G., and D. V. Goeddel. 1987. Heterologous expression and characterization of the human R-ras gene product. Mol. Cell. Biol. 7:2845-2856.

33. Marshall, M. S. 1993. The effector interactions of $p 21^{\text {ras }}$. Trends Biochem. Sci. 18:250-254.

34. Matsumoto, T., and D. Beach. 1991. Premature initiation of mitosis in yeast lacking RCC1 or an interacting GTPase. Cell 66:347-360.

35. McCormick, F. 1993. How receptors turn Ras on. Nature (London) 363:15-16.

36. Moodie, S. A., B. M. Willumsen, M. J. Weber, and A. Wolfman. 1993. Complexes of Ras-GTP with Raf- 1 and mitogen-activated protein kinase kinase. Science 260:1658-1661.

37. Moore, M. S., and G. Blobel. 1993. The GTP-binding protein $\mathrm{Ran} / \mathrm{TC} 4$ is required for protein import into the nucleus. Nature (London) 365:661-663.

38. Mosteller, R. D., J. Han, and D. Broek. 1994. Identification of residues of the H-Ras protein critical for functional interaction with nucleotide exchange factors. Mol. Cell. Biol. 14:1104-1112.

39. Novick, P., and P. Brennwald. 1993. Friends and family: the role of the Rab GTPases in vesicular traffic. Cell 75:597-601.

40. Perona, R., P. Esteve, B. Jiménez, R. P. Ballestero, S. Ramón, Y. Cajal, and J. C. Lacal. 1993. Tumorigenic activity of rho genes from Aplysia californica. Oncogene 8:1285-1292.

41. Polakis, P., and F. McCormick. 1993. Structural requirements for the interaction of $\mathrm{p} 21^{\text {ras }}$ with GAP, exchange factors, and its biological effector target. J. Biol. Chem. 268:9157-9160.

42. Quilliam, L. A., K. Kato, K. M. Rabun, M. M. Hisaka, S. Y. Huff, S. Campbell-Burk, and C. J. Der. 1994. Identification of residues critical for $\operatorname{Ras}(17 \mathrm{~N})$ growth inhibitory phenotype and for Ras interaction with guanine nucleotide exchange factors. Mol. Cell. Biol. 14:1113-1121.

43. Ren, M., G. Drivas, P. D'Eustachio, and M. G. Rush. 1993. Ran/TC4: a small nuclear GTP-binding protein that regulates DNA synthesis. J. Cell Biol. 120:313-323.

44. Rey, I., P. Taylor-Harris, H. van Erp, and A. Hall. 1994. R-ras interacts with rasGAP, neurofibromin and c-raf but does not regulate cell growth or differentiation. Oncogene 9:685-692.

45. Ricketts, M. H., and A. D. Levinson. 1988. High-level expression of c-H-ras 1 fails to fully transform Rat-1 cells. Mol. Cell. Biol. 8:1460-1468.

46. Ridley, A. J., and A. Hall. 1992. The small GTP-binding protein rho regulates the assembly of focal adhesions and actin stress fibers in response to growth factors. Cell 70:389-399. 
47. Ridley, A. J., H. F. Paterson, C. L. Johnston, D. Diekmann, and A. Hall. 1992. The small GTP-binding protein rac regulates growth factor-induced membrane ruffling. Cell 70:401-410.

48. Self, A. J., H. F. Paterson, and A. Hall. 1993. Different structural organization of Ras and Rho effector domains. Oncogene 8:655661.

49. Valencia, A., P. Chardin, A. Wittinghofer, and C. Sander. 1991. The ras protein family: evolutionary tree and role of conserved amino acids. Biochemistry 30:4637-4648.

50. Van Aelst, L., M. Barr, S. Marcus, A. Polverino, and M. Wigler. 1993. Complex formation between RAS and RAF and other protein kinases. Proc. Natl. Acad. Sci. USA 90:6213-6217.

51. Verrotti, A. C., J. B. Crechet, F. Di Blasi, G. Seidita, M. G. Mirisola, C. Kavounis, V. Nastopoulos, E. Burderi, E. de Vendittis, A. Parmeggiani, and O. Fasano. 1992. RAS residues that are distant from the GDP binding site play a critical role in dissociation factor-stimulated release of GDP. EMBO J. 11:2855-2862.

52. Vojtek, A. B., S. M. Hollenberg, and J. A. Cooper. 1993. Mamma- lian Ras interacts directly with the serine/threonine kinase Raf Cell 74:205-214.

53. Warne, P. H., P. R. Viciana, and J. Downward. 1993. Direct interaction of Ras and the amino-terminal region of Raf-1 in vitro. Nature (London) 364:352-355.

54. Wasylyk, C., P. Flores, A. Gutman, and B. Wasylyk. 1989. PEA3 is a nuclear target for transcription activation by non-nuclear oncogenes. EMBO J. 8:3371-3378.

55. Westwick, J. K., A. D. Cox, C. J. Der, M. H. Cobb, M. Hibi, M. Karin, and D. A. Brenner. Oncogenic Ras activates c-Jun via a separate pathway from the activation of extracellular-signal regulated kinases. Proc. Natl. Acad. Sci. USA, in press.

56. Zhang, X.-F., J. Settleman, J. M. Kyriakis, E. Takeuchi-Suzuki, S. J. Elledge, M. S. Marshall, J. T. Bruder, U. R. Rapp, and J. Avruch. 1993. Normal and oncogenic $\mathrm{p} 21^{\text {ras }}$ proteins bind to the amino-terminal regulatory domain of c-Raf-1. Nature (London) 364:308-313. 